\title{
III
}

\section{CONHECIMENTO HISTÓRICO NA ESCOLA DA INFÂNCIA: DIGRESSÕES SOBRE O ENSINO E O DIREITO À APRENDIZAGEM HISTÓRICA NO TEMPO DE VIVER E SER CRIANÇA*}

\begin{abstract}
João do Prado Ferraz de Carvalho
"Troquei as leituras vivas por manuais escolares" (Philippe Ariès) "O tempo histórico encontra, num nível muito sofisticado, o velho tempo da memória, que atravessa a história e a alimenta." (grifo do autor). (Jacques Le Goff)

“O espetáculo da busca, com seus sucessos e reveses, raramente entedia. É o tudo pronto que espalha o gelo e o tédio"
\end{abstract}

(Marc Bloch)

O historiador francês Phillipe Ariès em texto de 1946 intitulado "Uma criança descobre a história", narra de forma preciosa os dilemas envolvidos na sua aventura de descobrir e inquirir o mundo na relação com o tempo histórico e as narrativas sobre o passado.

A leitura desse provocante texto e a reflexão sobre as possibilidades de sua interpretação nos inspira a pensar sobre o ensino de história destinado às infâncias na sua relação com as diferentes formas de se viver esse tempo sociocultural de ser criança. Permite pensar sobre os dilemas envolvidos na escolarização do conhecimento histórico e inquirir as ações pedagógicas imbricadas nesse processo. Essa leitura nos inspira na reflexão sobre o conhecimento histórico escolar, suas possibilidades e responsabilidades formativas, nos instiga, enfim, a buscar sentido nas práticas escolares voltadas à imersão das crianças na reflexão sobre a aventura do homem no tempo ${ }^{1}$.

Ariès (1992) escreve no contexto francês de meados do século XX.

${ }^{*}$ DOI- 10.29388/978-65-86678-50-5-0-f.65-84

${ }^{1}$ As reflexões desenvolvidas neste texto não são totalmente inéditas, foram em parte publicadas pelo autor em outros textos (CARVALHO: 2018 e 2020) e acrescidas aqui de outras ideias e leituras. 
Narra que nasceu numa família realista nostálgica em relação a um passado glorioso e "grande apreciadora de memórias...", (p. 12). Conta-nos que apesar do gosto pela narrativa histórica fazer parte e ser elemento presente no cotidiano das suas relações familiares, entendia ter nascido num oásis e viver "fora da história". Condição essa justificada, segundo sua interpretação, por estar imerso na vida privada familiar e fechado às preocupações do exterior, à vida pública e coletiva, onde a história transcorria. Essa condição de vida, escreveu Ariès, "explica como não nasci dentro da História. (1992, p.10)

Quando na juventude resiste ao que considerava ser a memória fragmentada de sua família, e passa a buscar "o que ficava de fora". Escreve ter se tornado, assim, mais sensível "as zonas de sombra periféricas", o que "sublinhava a minha ignorância daquilo que ficava de fora de minhas leituras" (Ariès, 1992, p. 17).

A reação a essa memória familiar eivada de nostalgia e glória, a essa forma de representação do passado acrescida do lamento do tempo presente, vivida como uma prisão nos tempos idos no qual sua família teimava em permanecer, leva o jovem Ariès a buscar a História nos manuais escolares:

Durante minhas férias, passeava à beira mar - mal tinha catorze anos passeava pela praia com um velho manual do último ano de secundário [...] e me esforçava a valer por decifrar aquele conglomerado de datas e de factos despojados da mais pequena parcela de interesse. (1992, p.14)

Em determinado momento de sua formação, nem os manuais escolares lhes bastavam em sua busca por conhecer "toda a História, sem lacunas" (1992, p.17). Essa busca pela história total o leva a aprofundar-se na elaboração de quadros sinópticos, genealogia, cronologia, escreve quase como uma confissão que "lutava com os fatos para os forçar a reintroduzir-se no todo". (Ariès,1992, p. 16). Afirma, num tom aliviado meio ressentido, que teve dificuldades em se ver livre desses procedimentos.

Nesse percurso sumariado acima, acompanhamos Ariès criança adentrando à juventude buscando se distanciar das memórias familiares num primeiro momento, para posteriormente se reaproximar. $\mathrm{O}$ movimento primeiro entendia a História total como contraponto com a consequente rejeição das memórias, negadas como possibilidades de narrativa válida sobre o passado. Entendimento esse reavaliado num segundo movimento, assim descrito pelo historiador francês: 
[...] lamento-o hoje, e se tivesse que dirigir crianças apaixonadas pela história penso que as orientaria, pelo contrário, para esses testemunhos vivos. Sei que tais fragmentos contêm mais história, e mais história total, do que todos os manuais, mesmo os mais eruditos. (Ariès, 1992, p.17)

Ao iniciarmos nossas reflexões sobre o ensino de história na escola da infância buscamos inspiração na trajetória da criança Phillipe Ariès descobrindo a história. Com isso buscamos indicar que entre a vida pública e a vida privada de uma criança, entre as relações familiares e as relações estabelecidas na escola enquanto espaço primeiro de inserção no mundo público e coletivo, entre his tória e memória, há mais proximidades do que distanciamentos, independente das crianças serem ou não "apaixonadas pela história”.

Para prosseguir, uma nota para registro do uso específico que fazemos da leitura desse texto do historiador francês. Certamente não há sujeitos vivendo concretamente em oásis, apartados da história como processo, porque imersos na vida privada familiar. Na história "estamos e somos", como o próprio Ariès escreve (1992, p. 11). Na história estamos e somos sujeitos inseridos em diferentes perspectivas e formas de produção de nossa experiência. Experiência usada aqui no sentido que lhe atribui Edward Palmer Thompson (1981), em sua apaixonada obra $A$ Miséria da Teoria.

Aproximando essa reflexão dos objetivos deste texto, entendemos que o ingresso das crianças na escola enquanto materialização da passagem da vida privada à vida pública não representa o ingresso na história, mas uma mudança de perspectiva na relação com a história e com as memórias, familiares ou não.

Muda a perspectiva por ser função da escola destinada à infância levar crianças a pensarem sobre a produção coletiva da vida social, sobre as diferentes formas de sua organização ao longo do tempo, sem descartar outras formas de representações sobre o passado. Eis o papel da história enquanto conhecimento escolarizado tendo a "ciência dos homens" no tempo (Bloch, 2001, 55) como referência.

Essa mudança de perspectiva na vida das crianças implica o ingressar no mundo coletivo público, que não deve ser meramente apresentado às crianças, mas simbolizado, refletido, grafado, significado, compreendido. Materializando-se, assim, o papel social da escola na vida da criança na perspectiva da representação do que vem a ser a infância no tempo presente.

O ingresso no universo do mundo coletivo público mediado pela escola não deve comportar, em nenhuma hipótese, o silêncio e o esquecimento sobre a vida das crianças em outros espaços. Não pode implicar numa postura 
simplista que iguala aluno à criança, ignorando que são processos culturais complexos os responsáveis por tal representação. O aluno é uma invenção (Sacristán, 2005) e temos na modernidade um momento decisivo da construção dessa categoria como a grande referência de compreensão da criança (Boto, 2002, p. 14).

Quando esses seres adentram fisicamente os espaços escolares, os prédios escolares, e ultrapassam seus muros e portões, carregam consigo todos os dilemas humanos implicados no ser criança e viver uma determinada infância.

Crianças não se transformam em alunos naturalmente e adaptam comportamentos no sentido da escolarização passivamente. Resistem aos processos de disciplinarização de seus corpos e mentes. Os processos de escolarização, fundados e desenvolvidos na modernidade e relacionados ao tempo e ao espaço escolar, podem ser dolorosos às sensibilidades infantis.

De meados do século XX, tempo da escrita de Ariès, podemos nos movimentar em direção a um belo texto de Machado de Assis, Conto de Escola, que se passa em 1840 no Brasil Império vivendo o interregno entre o primeiro e o segundo Reinado, enfim, período Regencial. Da leitura desse conto saído da pena de um dos maiores escritores brasileiros, podemos intuir uma crítica mordaz a processos de escolarização centrados na perspectiva dos adultos.

Pilar, o menino personagem principal, exemplifica parte do dilema vivido pela infância escolarizada num mero olhar pela janela durante uma aula. Escreveu Machado de Assis dando vida a esse menino:

Para cúmulo de desespero, vi através das vidraças da escola, no claro azul do céu, por cima do morro do Livramento, um papagaio de papel, alto e largo, preso de uma corda imensa, que bojava no ar, uma cousa soberba. E eu na escola, sentado, pernas unidas, com o livro de leitura e a gramática nos joelhos.

Maravilhoso conto no qual a escola surge como lugar onde as crianças aprendem sempre, fator indicativo de seu potencial de socialização, mas nem sempre aprendem valores e atitudes contidos na expectativa dos adultos. No conto, o menino Pilar fica entre a delação e a corrupção, aprendida com seus pares no contexto das atividades escolares, ou seguir a companhia de batalhão e fuzileiros e "seu tambor à frente, rufando".

Acrescentemos aqui mais uma narrativa em tom de tempos amargos de 
escola. Essa vivida pela infância escolarizada no nosso tempo presente em um bairro considerado como periférico na grande metrópole São Paulo. Lugar longe, não por ser periférico, mas longe no sentido dos direitos das crianças.

Narrativa que chegou pelos cadernos e relatos de estudantes de Pedagogia $^{2}$ em curso de formação de professores e ganhou o seguinte contorno:

[...] a atividade estava relacionada à temática meio ambiente que a escola trabalhava como parte de seu projeto pedagógico, a necessidade, preservar o planeta e economizar um bem finito, a água. Fechar as torneiras na escola e em casa, não escovar os dentes com as torneiras abertas, não tomar banhos longos, não lavar o quintal com mangueiras, economizar água. Todas ações que um educador deve trabalhar com suas crianças. Entre o projeto e o lugar, o ser criança e o viver a infância num bairro com rodízio de água por problemas de abastecimento, perguntamos: como fazer as crianças fecharem as torneiras sem ferir o direito à água? Como educar para preservar o planeta no limite entre um dia com água e outro sem? (CARVALHO \& BARCELLOS, 2013, p. 40)

Certamente essa deve ser uma das preocupações para quem se dispõe a pensar o ensino de história destinado à infância escolarizada: o que fazemos com os desejos e expectativas dessas crianças, que nas narrativas aqui aludidas, seja ambientada em 1840, em meados do século XX ou na segunda década do século XXI, permitem questionar a invisibilidade da infância e o adultocentrismo? Como as relacionamos com esses seres que deixam de ser objetos para se tornarem sujeitos de direitos, conforme a legislação atual consagrada no Estatuto da Criança e do Adolescentes, o famoso ECA de 1990?

Essas reflexões permitem trazer à tona um questionamento que, na perspectiva aqui adotada, deve ser central: qual a abordagem histórica, ou melhor, qual deve ser a concepção de conhecimento histórico que, ao ser escolarizado, não desconsidera as crianças e as diferentes formas de viver infâncias na sua relação com o mundo a ser descoberto e inquirido por esses sujeitos? Como iniciar crianças na reflexão histórica sem negar sua vida privada e as memórias familiares?

Esses sujeitos de direitos não podem ser idealizados. Conforme escreve Vieira (2016, p. 84) inspirado em Arroyo (2006):

As considerações de Miguel Arroyo sobre o fim da idealização da vida

\footnotetext{
${ }^{2}$ Trata-se do curso de Pedagogia do Departamento de Educação da Escola de Filosofia, Letras e Ciências Humanas da Universidade Federal de São Paulo.
} 
social das crianças são conhecidas. Para ele, "as imagens românticas da infância se quebraram. É hora de preparar os professores para a infância real'. (ARROYO, 2006, p. 4). Na busca de sentidos, currículos e repertório educacional que alcance a criança real, o autor sugere que enquanto sujeito de direitos, os educandos devem conhecer a história de negação dos direitos humanos no Brasil. Desconstruir tal negação implica na elaboração de estratégias educacionais focadas nas questões de gênero, relações étnico-raciais e outros temas que, juntos, contribuam para efetivação de educação em direitos humanos.

Importante destacar que Arroyo (2004) cunhou a expressão "imagens quebradas" para buscar retirar da invisibilidade, crianças e jovens em ambiente escolar e se perguntar pela forma como os docentes estariam se relacionando com esses portadores de direitos: "os alunos colocariam seus mestres em um novo tempo? $(2004,9)$.

Oliveira (2011) escreve que algumas pesquisas do campo do ensino de história quando problematizam as especificidades de se ensinar história para crianças na escola "[...] convergem em alguns pontos, dentre os quais apresentamos dois: sobre a necessidade de se considerar a curiosidade infantil e sobre a significância que o conhecimento deve ter para o sujeito.” (p. 58)

Levar em consideração a curiosidade infantil e atentar para a importância de fazer com que o conhecimento seja significativo para a criança, sujeito cognoscente, impõe cuidados metodológicos, teóricos e conceituais que pretendemos discutir neste texto atento às considerações e ao alerta do historiador Phillipe Ariès: não trocar a história viva pelos manuais escolares, mantendo-se alerta diante dos perigos inerentes à busca do ensino de uma história total; prestar atenção aos perigos de se "esvaziar a história do seu conteúdo humano para a reduzir a um esforço de memória e a um esquema gráfico”. (1992, p. 21).

Ainda sobre resultados de pesquisas no campo do ensino de história, Oliveira (2011) chama a atenção para uma certa coesão em seus resultados quando apontam "para a importância no investimento metodológico aliado às concepções teóricas de que a criança deve aprender História da mesma forma que o historiador a escreve: como ação investigativa sobre o passado" (2011, p. 59).

Preocupação similar já estava presente nos Parâmetros Curriculares Nacionais de História proposto aos anos iniciais do Ensino Fundamental na década de 90 do século passado. Este documento já advertia que, embora o objetivo do ensino de história na escola da infância não seja formar pequenos historiadores, a metodologia do historiador deve ser a metodologia utilizada no ensino 
de história para crianças, pois

[...] a transposição dos métodos de pesquisa da História para o ensino de história propicia situações pedagógicas privilegiadas para o desenvolvimento de capacidades intelectuais autônomas do estudante na leitura de obras humanas, do presente do passado (MEC/SEB: 1997: p. 38 $39)$.

Nesse ponto de nossa reflexão, quando instados a pensar sobre a produção do conhecimento histórico na sua relação com aprendizagem significativa na escola da infância, pretendemos seguir acompanhados pelas ideias do historiador Marc Bloch.

Provocado por uma singela pergunta de seu filho, "Papai, então me explica para que serve a história", responde escrevendo um dos textos mais importantes e influentes sobre o métier do historiador, Apologia da História on ofício do historiador.

É nas páginas desse livro clássico que podemos ler o que está grafado abaixo:

[....] todo livro de história digno desse nome deveria comportar um capítulo ou (caso se prefira), inserida nos pontos de reflexão da exposição, uma série de parágrafos que se intitulariam 'como posso saber o que vou lhes dizer?' Estou convencido de que, ao tomar conhecimento dessas confissões, inclusive os leitores que não são do ofício experimentariam um verdadeiro prazer intelectual. O espetáculo da busca, com seus sucessos e reveses, raramente entedia. É o tudo pronto que espalha o gelo e o tédio (2001: p. 83)

Ensinar história nas escolas da infância não é ensinar historiografia, mas independente disso, não podemos lecionar sem iniciar as crianças na arte da desconfiança de todo e qualquer conhecimento que lhes seja apresentado pronto e acabado. Apresentado como revelação, o conhecimento histórico certamente gera desinteresse e tédio em relação à experiência da humanidade no tempo.

As crianças em processo de escolarização tornam o conhecimento histórico algo significativo para seu viver a infância quando o mundo não lhe é apresentado como uma revelação a ser aprendida, mas sim como um mundo a ser descoberto e quando elas são convidadas a participar dessa descoberta, quando sua natural curiosidade é respeitada em nome de valores humanos. 
Enfim, na esteira de Marc Bloch, uma constatação: quando a encenação do "espetáculo da busca" pelo conhecimento histórico escolar é resultante do envolvimento dos atores/sujeitos, as crianças, em todas as etapas do processo de criação, afastamos "o gelo e o tédio" e adentramos no campo das possibilidades da aprendizagem significativa.

Defendemos que são as indagações inerentes aos procedimentos de pesquisa do historiador que devem guiar os procedimentos metodológicos no sentido de propiciar a uma criança seu encontro com a história.

Para ruminar sobre as digressões apresentadas até então, recuperar o fôlego e continuar a jornada, retomo às inspirações contidas nas epígrafes deste texto: em Ariès um alerta sobre o que ensinar, em Marc Bloch uma sugestão do como ensinar, em Le Goff, uma sugestão do que não podemos esquecer.

Em melhor companhia, quase impossível!

Então, podemos seguir nessa aventura prazerosa de dialogar sobre a aprendizagem de crianças no tempo de viver e experienciar diferentes infâncias.

\section{Ensino de história na escola da infância e para a infância}

Apesar de já ter caminhado um bom pedaço nesse momento da travessia é importante tecer algumas palavras sobre o porquê usar o temo escola da infância e não simplesmente grafar, como está inclusive definido na legislação educacional, ensino de história na educação infantil e anos iniciais do ensino fundamental.

Em pesquisa sobre a implementação da escola primária graduada no estado de São Paulo entre 1890 e 1910, Rosa Fátima de Souza estudou a construção de um modelo de escola com a consequente produção de uma cultura escolar que, tomadas as devidas precauções, podemos afirmar que chegou aos nossos dias.

Extinta na legislação pela LDB 5.692/71 que criou o ensino de primeiro grau unindo primário e ginásio, a escola primária sobrevive, seja na memória de gerações que se referem aos anos iniciais do ensino fundamental como "primário", seja na dificuldade de integração dos atuais nove anos do ensino fundamental numa etapa coesa de formação em função da resistência de uma cultura escolar primária e ginasial, o que na leitura de Souza expressa "a existência de duas culturas escolares, duas organizações didático-pedagógicas, duas formas de conceber e praticar o ensino." $(1998,7)$

Portanto, podemos trabalhar com a ideia da existência de uma especifi- 
cidade da escola primária, de uma cultura primária a influenciar àquilo que atualmente chamamos de anos iniciais do ensino fundamental. Constatação essa que nos obriga a perguntar pela sua especificidade quando pretendemos entender o conhecimento histórico em sua conformação enquanto escola destinada à infância.

Essa cultura escolar primaria contempla a força de uma tradição inventada (Hobsbawm: 1984) que, além de resistir na memória de muitos que passaram pelos bancos escolares, também persiste em nosso tempo presente e influencia práticas pedagógicas nos espaços educacionais destinados às crianças de zero a cinco anos, qual seja, a escola de Educação Infantil.

Com a recente expansão da educação infantil no Brasil e com a criação do ensino fundamental de nove anos, essa cultura escolar primária tende a servir de referencial à escolarização de crianças em tempos de educação infantil, ou seja, a cultura escolar primária serve de modelo escolar à educação infantil como, por exemplo, indica a iniciação precoce aos processos de alfabetização. Estamos no campo da escolarização dessas crianças.

Objetivando dialogar com essa tradição inventada, é importante situar nosso debate no sentido da elaboração de uma escola estruturada a partir dos direitos da infância, que não desconsidere as reais necessidades das crianças de zero a 10 anos, atenta as etapas de desenvolvimento cognitivo, físico, psicossocial e cultural desses sujeitos de direitos, as crianças. Enfim, pensar numa escola da infância e para a infância.

No caso do ensino de história, estamos diante de um projeto a ser criado no embate com o que podemos chamar de resistências no contexto de uma tradição inventada. Presente como componente curricular nas escolas brasileiras desde o século XIX, a história enquanto conhecimento destinado às crianças esteve atrelado a vários projetos, seja de construção da nacionalidade, de formação moral e cívica, ou mais recentemente, de formação da cidadania. Diferentes projetos em diferentes contextos históricos que indicam mudanças no sentido da proposição dos objetivos formativos, o que também podemos chamar de proposições de mudança do currículo prescrito.

Porém, como as pesquisas no campo do currículo nos permitem afirmar, é entre o prescrito e o praticado, entre adesões e resistências, entre práticas e representações, que a escola e a formação se materializam. Assim, o "chão das escolas", adquire status de espaço privilegiado para pensarmos o que fazemos com nossas crianças ao viverem o tempo da infância escolarizada, no nosso tempo presente.

Do ponto de vista do conhecimento histórico escolar, a longa duração 
de práticas estruturadas a partir de uma concepção de história factual, linear, heroica, de matriz positivista e metodologicamente ensinada para ser assimilada passivamente mediante a memorização, sobrevive e resiste, apesar de tudo e de todos, em nosso tempo.

Tomemos uma questão de nosso tempo como indicativo. Apesar das propostas curriculares definidas pelo Estado brasileiro nos anos 90 do século $\mathrm{XX}$, representadas no caso do ensino de história pelos PCNs de História, terem sido amplamente difundidas, apesar das diversas políticas públicas desenvolvidas no sentido de sua implementação, assim como das mudanças implementadas no campo da produção e avaliação do livro didático, como o faz o PNLD desde o início dos anos 90 do século passado, alguns pesquisadores constatam que, embora assimilada no campo do discurso, no "chão da escola", o ensino de história ainda está atrelado à práticas distantes das prescritas pelas propostas inovadoras presentes em diversas políticas públicas (Soares (2009).

Ao tratar das especificidades do que denomina ensino de história nos anos iniciais, o pesquisador citado acima escreve que

Ele está mais vinculado às práticas curriculares cotidianas e à cultura escolar, portanto não se configura como conhecimento histórico escolar, na medida em que mantém distância considerável em relação à produção do conhecimento histórico-científico. (2009, p. 128).

Em outra passagem do mesmo texto, podemos ler:

Não surpreende aos pesquisadores o conhecimento de que a história ensinada está inserida na cultura escolar. Seja nas datas comemorativas ou nas festas juninas, a história é ensinada cotidianamente. Compreender que isso é parte do currículo oculto não é suficiente. O que os professores precisam é ter acesso ao conhecimento que a história produz ... (Soares, p. 134).

No diálogo crítico com esse pesquisador, nos interessa reter a constatação que nos permite trabalhar na perspectiva de uma ausência referente ao conhecimento histórico na escola da infância, apesar de todas as prescrições curriculares em sentido contrário. Constatação por nós entendida como resistência no contexto de uma cultura escolar inventada.

Convidamos outra autora para nos ajudar a construir um quadro aproximativo sobre os dilemas do conhecimento histórico na escola da infância.

Fonseca (2009), ao discutir o "lugar" do ensino de história nos anos 
iniciais do ensino fundamental, aponta para uma crise de identidade, produzida na esteira da criação dos Estudos Sociais como proposta a negar a especificidade tanto da história como geografia enquanto disciplinas específicas, com objetos próprios e questões específicas do ponto de vista curricular.

Acompanhando o raciocínio da autora, no contexto das reformas curriculares dos anos 80 e 90 do século XX, temos a proposta de superação dos Estudos Sociais e a retomada das disciplinas de história e geografia, como apresentado nos PCNs de 1997. Nesse momento, em função das consequências que a criação dos Estudos Sociais produziu, seja na formação de professores ou na elaboração de material didático, práticas negadoras das especificidades do conhecimento histórico, precisam ser superadas.

Fonseca afirma que nesse contexto de superação dos Estudos Sociais, torna-se comum em espaços de formação o questionamento dos professores sobre qual a especificidade do conhecimento de cada disciplina. Isso se manifesta em questões como: $\mathrm{O}$ que ensinar em Geografia? O que ensinar em História? Como distinguir abordagens históricas e geográficas ao trabalhar temáticas como família, bairro ou cidade? (2009, p. 246).

Seguindo ainda as interessantes análises desenvolvidas por essa autora, podemos falar de um "não lugar" do ensino de história na escola da infância, imbricados com outras questões como,

[...] a desvalorização social, política e pedagógica da História como conhecimento escolar e disciplina formativa; as características do processo de formação inicial dos professores; as concepções pedagógicas e de alfabetização dominantes; o perfil do material pedagógico e, em particular, dos livros didáticos de História e Geografia no período. (2009: p. 246)

À "ausência" apontada por Soares (2009) aludida acima e à "crise de identidade" discutida por Fonseca, podemos acrescentar a afirmação de Oliveira (2011) de que não temos

[...] uma concepção clara do significado, quanto a forma e ao conteúdo, do que seja ensinar História na escola para crianças. Há de ser diferente do trabalho com os anos finais, caso contrário por que não se institui a separação das disciplinas desde a entrada do sujeito no espaço escolar? $(2011 ; 60)$

Concordo com essa afirmação relativa às incertezas do que ensinar nos anos iniciais quando tratamos do conhecimento histórico. Entendo que essa 
constatação está relacionada à duas outras.

Primeiro às dificuldades de superação de uma tradição inventada no século XIX, estruturada numa concepção de formação moral e cívica presente nas propostas anteriores de ensino de história par a escola primária. A crítica a essa tradição inventada de formar a identidade nacional mediante a oferta de um ensino baseado nos grandes personagens e nos grandes acontecimentos, que do ponto de vista da aprendizagem das crianças exigia apenas a postura de memorizar fatos e datas, certamente objetivando uma formação moral e cívica, enfim, apesar das reiteradas críticas a essa tradição, vivemos um contexto educacional que não implica na produção de práticas escolares que permitam a aprendizagem histórica por parte das crianças.

Diante dessa crítica, duas posturas dos educadores: a manutenção das práticas no interior da cultura escolar ou, sem clareza do que fazer, muitos professores simplesmente não trabalham o conhecimento histórico com as crianças.

A segunda questão está relacionada à desconsideração das especificidades dos anos iniciais e das crianças enquanto sujeitos cognoscentes. Ou seja, é preciso pensar uma concepção de ensino de história na escola da infância que coloque como, principal preocupação as crianças, os sujeitos da aprendizagem.

Esta segunda constatação nos permite pensar sobre a especificidade do ensino de história na escola da infância na sua relação com outras áreas de conhecimento. Advogamos que não é o caráter disciplinar que deva prevalecer na organização do currículo dessa fase de escolarização de crianças e sim a perspectiva que toma o conhecimento em múltiplas dimensões. Considero importante trazer para essa discussão a preocupação com a epistemologia das ciências e áreas específicas que compõem o currículo dos anos iniciais do Ensino Fundamental, se perguntando sobre como fazer interagir diferentes objetos, perguntas e explicações sobre o mundo vivenciado pelas crianças.

Afinal, o que deve ser apropriado e explicado pelas crianças é o mundo em que vivem e produzem suas infâncias, que embora estudado em diferentes perspectivas pelas diversas ciências, não pode soar como fragmentado e disperso.

O conhecimento histórico deve desempenhar papel relevante nessa descoberta por parte das crianças em função de seu potencial formativo. Concordamos com Menezes e Silva, quando escrevem que

[...] é possível e necessário trabalhar História com alunos das séries iniciais, na compreensão de que eles são capazes de questionar, de pesquisar, 
de relacionar, de temporalizar, de conceituar, respeitadas as experiências e o acervo dos conhecimentos pertinentes à faixa etária a que pertencem. (2004, p. 266)

Portanto, o ensino de história na escola da infância não deve ser disciplinarizado e devemos tomar muito cuidado com certa leitura, digamos, imperialista, da área de história, ao discutir e "invadir" o espaço destinado ao ensino de crianças. Se isso já é um problema em níveis mais elevados da escolarização, na escola da infância, é inconcebível.

Não podemos perder a dimensão histórica das disciplinas escolares (Chervel:1990). Resultantes de processos e práticas culturais relacionadas ao tempo de sua produção no âmbito da cultura escolar, devem ser entendidas em suas especificidades na relação com as ciências de referência e suas epistemologias e inquiridas sobre o porquê de sua prescrição curricular e processos culturais de legitimação de seus saberes (Martins 2002) em nosso tempo presente, tempo no qual se questiona tanto a naturalização da escolarização de crianças em contextos conflituosos com seus direitos de aprendizagem como a aparente naturalidade das disciplinas escolares (Bittencourt, 2003, p. 9).

Aprender e ensinar história na escola da infância deve levar em consideração a forma como as crianças vivem e produzem sua infância lendo o mundo, como se desenvolvem do ponto de vista cognitivo, psicológico, físico, etc.

Essa leitura do mundo se torna empobrecida sem uma formação que incorpore à explicação a dimensão temporal dos fenômenos humanos, porém, devemos ser cuidadosos com a disciplinarização do currículo nessa fase de formação escolar.

Devemos nos posicionar sobre o ensino de história na escola da infância a partir de uma leitura que implique aproximar-se do campo da educação em várias perspectivas. Na perspectiva da compreensão das diversas dimensões envolvidas nos processos de aprendizagem, nos debates sobre alfabetização e letramento, na apropriação das discussões sobre as diferentes infâncias, suas histórias, suas especificidades, sua produção pelas crianças na relação com seus pares e com os adultos.

\section{Ensino de história, memória e sujeitos de direitos em processo de escolarização}

Começo perguntando: é possível discutir o ensino de história na escola da infância desconsiderando o conceito de infância? Afinal, é este conceito so- 
ciocultural que nos permite refletir sobre as diferentes formas de ser e viver das crianças, sujeitos cognoscentes produtores de diferentes infâncias. Permite-nos perguntar como o ser criança apresenta-se ao mundo e é por ele apresentado em diferentes contextos, mundo esse que o ensino e a aprendizagem escolar pretende que esse ser pense, descubra, critique, e o tome como uma produção sua enquanto sujeito histórico.

É preciso pensar os estudos sobre a infância em suas múltiplas perspectivas para avançarmos na discussão sobre o ensino de histórica, formulando perguntas sobre qual a concepção de infância que nos orienta a pensar os processos de ensino e aprendizagem?

Faz-se necessário incluir neste debate a defesa da aprendizagem como um direito das crianças, e não das famílias ou da sociedade. Estamos no campo da infância portadora de direitos, uma forma de conceber o viver a fase criança dos seres humanos.

Isso implica em situar o sujeito cognoscente em função de suas especificidades produzidas num tempo e espaço determinados. No tempo presente concebe-se com naturalidade que lugar de criança é na escola, por isso devemos ficar atentos, se perguntando sobre essa naturalização e seus desdobramentos, se perguntando sobre os processos de produção de uma infância escolarizada.

Especificamente sobre o conhecimento histórico escolar, é fundamental assinalar que não há, nem deve haver, uma proposta única de ensino de história para a escola da infância. O que há é a necessidade de, fundamentado pela epistemologia da ciência histórica, se perguntar pelas formas de elaboração de propostas que considerem o múltiplo, o plural, as diferentes identidades, o diverso, no diálogo com outras áreas do conhecimento, principalmente com a educação.

Ou seja, é preciso se perguntar sobre as diferentes formas de se viver as infâncias pelas crianças inseridas no processo de escolarização. Enfim, é preciso se aproximar das temáticas próprias da escola da infância para pensar o ensino de história na educação infantil e nos anos iniciais do Ensino Fundamental.

Entre as várias questões envolvidas nessa afirmação, o tema da alfabetização e letramento ganha relevância.

Inspirada pelas reflexões de Paulo Freire, Fonseca (2009) pensa "sobre a impossibilidade de separar a leitura e a escrita da palavra da leitura do mundo, da leitura da história”, o que a leva a seguinte afirmação:

Leitura, compreensão, palavra, texto. Ler o mundo implica romper com generalizações, simplificações e fragmentação no/do processo educativo. 
Se "ler" é "ler o mundo", não podemos aprender a ler as palavras sem a busca da compreensão da História, da Geografia construídas pelos homens, compreensão das coisas do mundo, das experiências humanas, das relações sociais, de trabalho, de tempo. Isso requer de nós uma outra concepção de História, de ensino e aprendizagem da Língua" (2009, p. 252).

A história enquanto conhecimento formativo que nos ajuda a compreender o mundo, "não pode ser ensinada separada, isolada do processo de alfabetização da criança e do adulto", é um "equívoco separar a compreensão da História da leitura e da escrita" (Fonseca, 2009, p. 252 - 253).

As afirmações de Fonseca sobre alfabetização e letramento são fundamentadas a partir das reflexões de Magda Soares (2004), uma das autoras que também serve como referência para programas e documentos importantes que em nosso tempo presente discutem propostas de escolarização da infância.

Em publicação da Secretaria de Educação Básica do MEC destinada a formação dos professores e sua atuação no contexto do Programa Nacional de Alfabetização na Idade Certa (PNAIC), podemos ler: "alfabetizar na perspectiva do letramento também é compreender que se ensina para que as crianças sejam sujeitos capazes de expor, argumentar, explicar, narrar, além de escutar atentamente e opinar..." (BRASIL/MEC/SEB, 2012, p. 11).

Ao discutir os direitos de aprendizagem histórica no ciclo de alfabetização, encontramos nesse documento a defesa de que esse é um direito da criança, garantido pela Lei de Diretrizes e Bases da Educação Nacional, Lei 9.394/96, conforme estipulado no inciso II do seu Artigo 32, que determina que faz parte da formação básica do cidadão oferecida do Ensino fundamental, ou seja, as crianças têm direito a "compreensão do ambiente natural e social, do sistema político, da tecnologia, das artes e dos valores em que se fundamenta a sociedade" (BRASIL/MEC/SEB, 2012, p. 29).

Portanto, assim como a alfabetização e letramento são direitos das crianças, e é impossível alfabetizar e letrar sem história, a aprendizagem histórica é um direito da criança e compõe uma das formas de se compreender a infância em nosso tempo presente.

$\mathrm{O}$ direito da criança à aprendizagem histórica certamente está relacionado ao direito de ter sua história, sua memória e a de sua família e comunidade, tratadas como uma das preocupações na escola da infância.

A vida privada e as memórias familiares estão eivadas de possibilidades de servirem como ferramenta inspiradora de diálogos frutíferos que inspirem e 
possibilitem às crianças compreenderem a história pública e coletiva sem descartar a vida privada e familiar.

O conhecimento histórico na escola da infância deve levar em consideração as diferentes formas da humanidade se relacionar com o tempo histórico, com as diferentes formas de se ler o passado no tempo presente das crianças, atentar para elaboração sociocultural de múltiplas narrativas sobre a aventura de homens e mulheres no tempo. Enfim, não podemos incorrer no engano de desconsiderar a vida social das crianças e suas leituras de mundo produzidas para além das narrativas históricas escolares, desconsiderando memórias familiares e de grupos comunitários no bairro.

Ao ingressar na escola e no universo das preocupações com a vida pública e coletiva, as diferentes infâncias estão imersas em memórias e maneiras de experienciar, no sentido thompsoniano (1981), o viver a fase criança e o produzir de uma determinada infância. Devemos, assim, tomar essa preocupação geracional como elemento estruturador do modo de compreender e produzir currículos e práticas na escola das infâncias.

A aprendizagem sobre o tempo, matéria fundamental da história, deve ultrapassar as preocupações cronológicas registradas nos calendários e nos esforços de periodização. Certamente o trabalho pedagógico não pode prescindir dessas formas de mensurar o tempo histórico, porém devemos ficar atentos ao que escreve Le Goff:

Hoje, a aplicação à história dos dados da filosofia, da ciência, da experiência individual e coletiva tende a introduzir, junto destes quadros mensuráveis do tempo histórico, a noção de duração, de tempo vivido, de tempos múltiplos e relativos, de tempos subjetivos ou simbólicos. O tempo histórico encontra, num nível muito sofisticado, o velho tempo da memória, que atravessa a história e a alimenta." (grifo do autor). (Le Goff, 1994, p. 13).

Memória, elemento essencial na constituição das identidades individuais e coletivas, lugar "onde cresce a história, que por sua vez a alimenta, procura salvar o passado para servir o presente e o futuro. Devemos, assim, trabalhar de forma a que a memória coletiva sirva para a libertação e não para a servidão dos homens" (Le Goff, 1994 p. 476 e 477).

Levar essas leituras em consideração implica incorporar como procedimento analítico que o passado é lido de forma diferente por diferentes grupos que produzem diferentes narrativas. Não há uma infância, mas infâncias vividas 
por diferentes crianças. Por isso, certamente, há diferentes formas de se relacionar no presente com o passado. É preciso avançar a necessidade de discutir a invisibilidade da infância em nosso tempo presente na relação com os processos de escolarização e questionar o ensino de história na escola da infância que não considera a criança na perspectiva temporal, como sujeito histórico.

Inspirado pelas memórias de um adulto sobre os dilemas de uma criança descobrindo a história, como podemos ler na narrativa do historiador Phillipe Ariès sumariada na abertura deste texto, e concebendo a relação entre história e memória na perspectiva de Le Goff, para quem a memória coletiva" tem uma forma científica, "a história" $(1994,535)$, tomo como princípio que essas devem ser preocupações inseparáveis dos educadores que pretendem formar crianças, esses sujeitos de direitos.

\section{Referências}

ARROYO, Miguel G. Imagens quebradas. Trajetórias e tempos de alunos e mestres. Petrópolis: Vozes: 2004.

. Entrevista. In: Revista Criança, MEC, Brasília, 2006, p. 3-7.

ASSIS, Machado de. Contos de Escola. Obra Completa. Rio de Janeiro: Nova Aguilar 1994. v. II.

ARIÈS, Philippe. Uma criança descobre a história. In: ARIÉS, P. O tempo da História. Lisboa: Relógio D’água, 1992; p. 9-21.

BITTENCOURT, Circe Maria Fernandes. Disciplinas escolares: história e pesquisa. In: OLIVEIRA, M A. T \& RANZI, S. M, F. História das disciplinas escolares no Brasil: contribuições para o debate. Bragança Paulista: EDUSF, 2003.

BLOCH, Marc. Apologia da História ou o ofício do historiador. Rio de Janeiro: Zahar, 2001.

BOTO, Carlota. O desencantamento da criança: entre a Renascença e o Século das Luzes. In: FREITAS, M. C \& KUHLMANN JR., M. Os intelectuais na história da infância. São Paulo: Editora Cortez, 2002, p. 11 - 60.

BRASIL. Secretaria de Educação Fundamental. Parâmetros curriculares nacionais: história e geografia. Brasília: MEC/SEF, 1997. . Secretaria de Educação Básica. Pacto Nacional pela Alfabetização 
na Idade Certa. Planejamento escolar: alfabetização e ensino da Língua Portuguesa. Brasília: MEC/SEB/DAGE, 2012.

CARVALHO, João do Prado Ferraz de \& SILVA, Jorge Luiz Barcellos da. Direito à identidade e à territorialidade. In: FINCO, Auad (org.). Educação Infantil e Direitos da Infância. Recife: Pipa Comunicação, 2013, p. 31 - 42. CARVALHO, João do Prado Ferraz de. Dialogando sobre o conhecimento histórico na escola da infância no contexto das ações do Pibid e do Programa de Residência Pedagógica do curso de Pedagogia da Unifesp. In: CARVALHO, J.P.F; SILVA, J.L.B; SILVESTRE, M.A. Pibid Unifesp em Diálogo. Trajetórias e Indagações sobre Práticas de Formação Inicial de Professores. Jundiaí, SP: Paco Editorial, 2018, p. 149 - 167.

. O Ensino de história nos anos iniciais do Ensino Fundamental e a educação para as relações étnico-raciais: reflexões acerca de experiência de enfrentamento do racismo no Brasil. In: BAUMGARTEN, Lídia. História Uma disciplina sob suspeita. Reflexões, diálogos e práticas. Curitiba: CRV, 2020, p.103 - 117.

FONSECA, Selva Guimarães. É possível alfabetizar sem "História”? Ou... Como ensinar História alfabetizando? In: FONSECA, S. G. (org.). Ensino Fundamental. Conteúdos, metodologia e práticas. Campinas: Alínea Editora, 2009; p. $241-265$.

HOBSBAWN, Eric. Introdução: A invenção das tradições. In: HOBSBAWM, E. \& RANGER, T. (orgs.). A Invenção das Tradições. Rio de Janeiro: Paz e Terra, 1984, p. $9-23$.

LE GOFF, Jacques. História e memória. Campinas: Editora da UNICAMP, 1994.

MARTINS, Maria do Carmo. A História prescrita e disciplinada nos currículos escolares: quem legitima esses saberes? Bragança Paulista: EDUSF, 2002.

OLIVEIRA, Sandra Regina Ferreira de. A progressão do conhecimento histórico na escola. In: FONSECA, S. G. \& GATTI JÚNIOR, D. (orgs.) Perspectivas do ensino de história: ensino, cidadania e consciência histórica. Uberlândia: Edufu, 2011, p. 57 - 66.

SILVA, Maria Fatima de Souza \& MENEZES, Leila Medeiros de. Ensinando história nas séries iniciais: alfabetizando o olhar. In: MONTEIRO, A. M; GAS- 
PARELOLO; A, M. \& MAGALHÃES, M. S. (orgs.). Ensino de História. Sujeitos, saberes e práticas. Rio de Janeiro: Mauad X: FAPERJ, 2007, p. 215 228.

SACRISTÁN, José Gimeno. O aluno como invenção. Porto Alegre, Artmed Editora, 2005.

SOARES, Magda. Letramento e alfabetização: as muitas facetas. Revista Brasileira de Educação, n. 25, p. 5-117, jan./ abr., 2004.

SOARES, Olavo Pereira. O Ensino de História nos Anos Iniciais e a formação dos professores. In: FONSECA, S. G.(org.) Ensinar e Aprender História: formação, saberes e práticas educativas. Campinas: Alínea Editora: 2009; p. 127 -147 .

THOMPSON, E. P. A miséria da teoria ou um planetário de erros: uma crítica ao pensamento de Althusser. Guanabara: Zahar Editores, 1981.

VIEIRA, Cleber Santos. A criança e o direito à memória. Revista Interdisciplinar de Direitos Humanos. Bauru, v. 4, n. 1, p. 83-96, jan./jun., 2016. 